\title{
A proposed strategy to encounter extremist ideology on Egypt's frontier governorates: North Sinai case
}

Strategy to encounter extremist ideology

Mohamed O. Elkhosht

Faculty of Arts, Cairo University, Giza, Egypt

Mahmoud Mahmoud

Faculty of Economics and Political Science, Cairo University, Giza, Egypt

Ahmed Zayed and Mo'taz S. Abdallah

Faculty of Arts, Cairo University, Giza, Egypt, and

Mohamed S. A. Kharbush and Dalal Mahmoud

Faculty of Economics and Political Science, Cairo University, Giza, Egypt

\begin{abstract}
Purpose - This study aims to investigate the relationship between the spread of extremist thoughts and the weak economic and social factors surrounding it. There are higher chances of better understanding of this relationship on Egypt's borders more than its center. Achieving development and stability leads to creating a preventive environment to extremist thoughts existence and spread, in addition to preventing its transformation into terrorism.

Design/methodology/approach - The study depends on an analytical methodology to examine the validity of the research hypothesis through two basic steps. The first step depends on describing the geographical, demographical, economic, social, political and security aspects of North Sinai. The second step is a prospective approach to build a strategy that helps in achieving development and accordingly a comprehensive confront for the opportunities of extremist thought spreading in North Sinai.

Findings - The study concludes that Egypt is well aware of the dimensions of encountering extremist thoughts and has adopted a comprehensive approach in achieving this. It has already started the paces of this confrontation in general, with some specificity in North Sinai Governorate that observed lately increased activities by extremists and terrorist groups. The proposed strategy is a set of policies that can help the country achieve its goals against extremism and terrorism.
\end{abstract}

Research limitations/implications - The study covers a time frame that starts from 2014, which is considered the beginning of a new phase for the Egyptian state. The study relies on the field of strategic studies and it focuses on North Sinai Governorate.

(C) Mohamed O. Elkhosht, Mahmoud Mahmoud, Ahmed Zayed, Mo'taz S. Abdallah, Mohamed S. A. Kharbush and Dalal Mahmoud. Published in Journal of Humanities and Applied Social Sciences. Published by Emerald Publishing Limited. This article is published under the Creative Commons Attribution (CC BY 4.0) licence. Anyone may reproduce, distribute, translate and create derivative works of this article (for both commercial and non-commercial purposes), subject to full attribution to the original publication and authors. The full terms of this licence maybe seen at http:// creativecommons.org/licences/by/4.0/legalcode

The authors would like to thank the editor and the anonymous reviewer for their helpful comments.

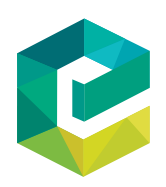

Received 9 August 2020 Revised 19September 2020 Accepted 20 September 2020 
JHASS

3,2

Originality/value - The study has a scientific importance because it presents a proposal for a comprehensive strategy to encounter extremist thoughts, which adds value to the literature of the study of extremism. The current study makes its contributions in some directions, such as reviewing the contents of this extremist thought or the juristic comment on it, the impacts of the spread of extremist thoughts, the role of the official media in disseminating extremist thoughts or standing up to it. In terms of application, the study presents a proposal with many policies in various fields to counter extremist ideology. These proposals are implementable in North Sinai Governorate as well as other frontier governorates.

Keywords North Sinai, Extremism, Comprehensive development, Motives for extremism,

Encountering extremism

Paper type Research paper

\section{Introduction}

The 2015 United Nations Counter-Terrorism Strategy confirmed strong relationship between extremism and terrorism. In its resolution 2178 (2014), the Security Council highlighted the connection among extremism, violent extremism and terrorism. It stressed on the importance of the conformity of the measures taken to confront it with international norms. Moreover, the Security Council resolution recognized the need for preventing extremism. Extremism that rises to terrorism requires collective efforts, including preventing the spread of extremist thoughts among individuals, recruiting and mobilizing them to join terrorist groups. This strategy has affirmed that a more full-throated approach is needed not only for the basic security measures being taken to combat terrorism, but also for using systematic preventive measures that directly address the drivers of extremism, which provide an incubator environment for the growing presence of terrorist organizations and activities. Several studies have concluded that the environment incubating extremism, and hence terrorism, is associated with a weak role/presence of the state institutions.

The Egyptian state has realized this fact while fighting against terrorism that threatens all efforts for development and stability. Accordingly, the Egyptian state has adopted a comprehensive strategy to combat terrorism. These efforts begin with preventing the existence of extremism that helps terrorist organizations to build themselves on. In addition, the Egyptian state seeks to achieve comprehensive and sustainable development that benefits the current and future generations. With the greatest challenges facing all parts of the state, these challenges mount in the frontier governorates, especially North Sinai, where the most terrorist operations have occurred since 2013. However, the Egyptian state believes that development and construction are the basis for stability and are the primary tools to subvert the structure underpinning extremism and terrorism.

Cairo University, as one of the most prestigious educational institutions in Egypt, seeks to play an active and constructive role in confronting extremism. It also believes that enlightened thought and flares of science and knowledge can come up against extremist thoughts. Cairo University is also fully aware of its social responsibility, its role in serving the society and coming to grips with the society's problems through proposals and recommendations put forward to the decision-making circles. Hence, it aims at presenting one of a series of studies in which the university intends to make good use of the professors and students' mindsets through their participation in the comprehensive and sustainable development battle, in which the state is involved. Through this study, Cairo University also hopes to achieve its goal of changing the incubator environment for extremist thoughts in North Sinai.

\section{Problem statement}

The study aims at clarifying the environmental conditions in North Sinai, especially the economic and social conditions, to answer the following research question: 
RQ1. To what extent does this environment provide fertile ground for the growth of extremist ideas and thus terrorism?

This question leads to another sequence of major questions presented in the following:

Strategy to encounter extremist ideology

Q1. How does the state stands up to this incubator environment for extremist ideas?

Q2. Are the measures that the state has been adopting enough?

Q3. Could the state suggest more measures?

This study is concerned with a period from 2014 until present. This period marks a new stage in the life of the Egyptian state and clarifies how the state has adopted clear directions to stand up to extremism and terrorism, and then how it followed a comprehensive strategy for development in Sinai.

Although there are different states, and cities are suffering from terrorism with a different experience, but Sinai is a special case for many reasons such as its history, the demographic aspects and its neighborhood. So the comparative approach might be useful if the main focus of the paper concentrates on general strategy for counter terrorism, but it concentrates on a preventive strategy to prevent violent extremism.

Moreover, the study indicates various elements of the environment surrounding the Northern Sinai region, at both the security and political levels and with a focus on the economic and social dimensions. This is because of several considerations; the most important is the stability of the political system in Egypt during the study period and the adoption of clear development policies in Sinai. In addition to the special nature of Sinai as a frontier region, Sinai has moral and symbolic privacy because of Egyptian martyrs in different wars throughout history and those martyrs while countering terrorism (Abdel-Rahman, 2001). Besides, there is that material specialty of Sinai after Egypt's taking on those obligations of the peace treaty with Israel, as it is the land connected to the Gaza Strip suffering under the rule of Muslim Brotherhood-affiliate Hamas since 2007. On the other side, the Egyptian armed forces' responsibility for the security confrontation with terrorist groups in Sinai marks the security environment with specific characteristics that are not an object of this study.

The primary focus of this study is placed on the economic and social dimensions for several considerations, the most important of which is the relatively little interest shown by the Egyptian state in social and economic services during the previous decades. Regardless of the reasons for such little interest, the result is that there is an accumulation of lengthy absence of the central state's role in the face of that increasingly influential role of domestic powers. This has also had an impact on the cultural aspects of Sinai, as the local culture and primary links take higher priority than the national ties and culture. This should not be understood as a suspicion of the patriotism or loyalty of the citizens of Sinai to the Egyptian state. Rather, it can be considered that the previous absence of the state's role has relatively reduced the confidence of these citizens. Thus, sustained, all-out efforts are required to establish the state's credibility to its policies on the development and stability of Sinai (Hilal, 2018). Another repercussion of the retreating role of the state is that the extremist terrorist organizations seized the chance and tried to appear as an alternative to the state, especially among those of low-level education, the illiterates or the poorest and most needy sections of the Sinai community.

The study aims at testing the validity of the following hypotheses: 
JHASS

3,2

86

H1. Weak economic conditions (poverty levels and average wages) and social conditions (mainly education and health) provide a favorable environment for accepting and growing extremist thought.

H2. The negative impact of these weak economic conditions increases in regions more distant from the state's center taking North Sinai as a model.

Thus, the study is divided into two main parts.

\section{First part: environmental characteristics surrounding North Sinai \\ Governorate}

The environment surrounding North Sinai Governorate has several characteristics that are reviewed as follows:

\section{Geographical and demographic environments}

- The total area of North Sinai covers $27,564 \mathrm{~km}^{2}$ (2.8\% of the republic's area). The inhabited area is $1,588 \mathrm{~km}^{2}$, equivalent to $7.2 \%$ of the total area of the governorate. The expansion of the uninhabited area has helped provide space for terrorist organizations, both for training and for hiding away.

- Its capital is the city of El-Arish, and the governorate is divided into six administrative centers: Rafah, Sheikh Zuweid, El-Arish, Bir Al-Abed, Al-Hasna and Nakhl. It also has 473 villages and 85 local units.

- According to the Central Agency for Public Mobilization and Statistics' (CAPMAS) Statistical Yearbook issued in January 2020, North Sinai has a population of $470,707,0.5 \%$ of the total population of Egypt. The number of males is 239,548 and the number of females is 231,159 . The percentage of the inhabited area to the governorate's total area is $7.2 \%$. El-Arish city is the first population base of North Sinai with about $41.2 \%$ of the total population of the governorate, while the population density is relatively low in Sheikh Zuweid, which makes it one of the hotspots of terrorist elements in North Sinai.

- The geographical and topographical nature of North Sinai provides many development components in mining, tourism, trade, construction and agriculture sectors upon which the strategic plan for the development of the governorate builds (Amin, 2016). The 2030 sustainable development strategy for North Sinai includes several projects - most of which have already come into effect - that depend on these components.

\section{Economic environment}

Many findings can be drawn from the official statistics on North Sinai. The most important points are the following:

(1) North Sinai's unemployment rate has significantly increased to include $48.2 \%$ of the governorate's total population, and $1.9 \%$ of the nation's total unemployment rate. This ratio is striking as it reflects an increase in the financial needs of multiple groups, which maximizes their chances of receiving extremist ideas or being drawn toward terrorist groups. According to the most recent statistics issued by the CAPMAS in 2018, the number of employed individuals (15 year olds and above) in 2018 in North Sinai was 113,200 people, which is about $0.4 \%$ of the 
total number of the employed citizens in Egypt. The number of males is $69,600-$ $61.5 \%$ of them are employed - while the number of females is $43,600-38.5 \%$ of them are employed. The total number of unemployed citizens in North Sinai (between the ages of 15 and 64 years) is 54,600 divided into 22,500 males, representing $32.3 \%$ of the total number of males, and 32,100 females, representing $73.6 \%$ of the total number of females in the governorate. The unemployment rate in North Sinai was $48.2 \%$ in 2018. Therefore, the 2030 sustainable development strategy for North Sinai is to help provide more than 164,630 job opportunities in various sectors.

(2) The need to work on developing North Sinai's infrastructure (electricity supply, water supply and natural gas supply services) as the cities of North Sinai, until 2017, were the least connected to the public sewage networks in the governorate among the rest of the governorates of Egypt. Several projects have been implemented to develop the infrastructure there, starting with improving the road network, constructing 24 roads with a total length of $1,922 \mathrm{~km}$, and fostering development in the field of agriculture as it is the largest traditional activity for the people of the Sinai Peninsula in addition to grazing and fishing (Amin, 2016). The cultivated areas in Sinai are estimated at 175 thousand acres, 173.5 thousand acres of which are in North Sinai. Additionally, a number of major projects have been initiated to make a radical change in the water resources in Sinai by transferring water to it from the Nile River, such as the Al-Salam Canal and Al-Dafswar Siphon projects. In respect of the water supply services, 49 projects are being implemented, including desalination plants and water purification stations. As for the electricity supply services, six projects are being carried out to boost the efficiency of electricity networks in the cities of Rafah, Sheikh Zuweid and ElArish.

(3) A total of $\$ 275 \mathrm{bn}$ were allocated to implement the development strategy in Sinai, which aims at providing 1 million job opportunities, injecting investments with a total worth of $\$ 20 \mathrm{bn}$ and raising Sinai's share of the gross national income to $4.5 \%$. Within the framework of this strategy, several measures have been taken, including:

- Establishment of a joint stock investment company, which is the Sinai Investment and Development Company aiming primarily at developing North and Central Sinai regions and transforming them into an integrated development community.

- The total number of implemented and targeted projects during the 6 years from 2014 to 2020 is expected to be 994, at an estimated cost of EGP795bn. A total of 751 projects were also carried out in 21 sectors since mid-2014 until March 2019, with a total investment value of EGP357.7bn. Besides, 243 projects are being implemented with a total investment value of EGP437bn, to be completed in June 2020.

- Government investments were made with a total worth of EGP2.98bn during the 2018-2019 fiscal year to develop the governorates of North Sinai and South Sinai, i.e. $3 \%$ of the total public government investments back then. It is a very high percentage compared to the population of the two governorates. A total of $86 \%$ of these investments were financed by the public treasury with a total 
JHASS

3,2

88 worth of EGP2,553m, a 32\% raise compared to the 2017/2018 fiscal year and up from EGP1.93bn.

- Egypt's Vision 2030 focuses on promoting industrial development in Sinai through a number of industrial projects, including the implementation of four projects. The most important projects are preparing the infrastructure of the northwestern part of Sinai, and the service area of the industrial zone of Bir AlAbed. A wholesale market in El-Arish is also being established on an area of 38.8 acres, including exhibitions of vegetables, fruits, fish, meat and poultry. Moreover, a complex for the production of marble has been established in Gifgafa, with four production lines and a production capacity of 3 million $\mathrm{m}^{2}$ annually. Additionally, an industrial zone on an area of 63 million $\mathrm{m}^{2}$ and fishponds in East Port Said on an area of 19,351 acres with 5,906 ponds have been created. A free fishing lake in East Port Said on an area of 10 acres and a fishing port in Romani have also been established.

\section{Social environment}

(1) Education is a major component of the social environment. In North Sinai, according to the 2018-2019 statistics, the illiteracy rates in urban and rural areas were $19.4 \%$ and $9.6 \%$, respectively. This is a paradox attributed to the fact that education in the countryside is a means for improving living standards.

(2) Reorientation for education budget in North Sinai to raise the quality of education in North Sinai, and here are some suggestions:

- In this regard, it is proposed to provide some exceptional incentives for North Sinai students, such as school meals and educational tools.

- A close follow-up of pupils to reduce dropouts from education, especially in the basic education stage.

- Establishing an infrastructure that enables distance learning and providing trainings in how to use it gradually. This may help reduce school dropout rates.

- Providing cash and in-kind support to families with one or more children to reduce the rates of dropping out of education. This support should be linked to the attendance of children in schools so that it is granted according to the child's attendance rate in school, taking into account increased support in the case of females to encourage families to pursue female education.

- Preparing an educational program for dropouts who cannot go back to school. $(*)$

- Holding competitions between different schools to encourage competition and proficiency, while offering appreciation and honorary awards to students, teachers and winning schools. (*)

- Establishing a number of technical schools that provide vocational applications after the basic education stage to suit the societal nature of the local population. In addition, building partnerships between technical education schools in the governorate and specialized factories should be adopted to train and recruit technical school graduates. $(*)$ 
- There is a high rate of dropouts from basic education, where the percentage of those who have not enrolled and dropped out is $33.72 \%$ among the total number of children aged between 6 and 18 years old. The rate of dropouts among males is $28.15 \%$, because of the low economic conditions of the families, and this has resulted in males dropping out of education to work, and the drop of marriage age of females. The illiteracy rate is also increasing in the governorate, especially among females (Murad, 2019).

- School density is moderate - about 31 students per class - especially with the increase in the number of schools by $2.6 \%$ between 2018 and 2019. The following figures show the percentage distributions of teachers and students across the different educational stages/levels in North Sinai in the 2018/2019 academic year (Figure 1).

(3) North Sinai is characterized by a student-teacher ratio that matches the international standards. In the elementary educational stage, the student-teacher ratio is $1: 14$. This ratio is also 1:9.9 and 1:8 for the preparatory and the secondary educational stages, respectively. This can be attributed to the governorate's "under-population," coupled with the increasing number of teachers in the various educational stages.

2018/2019 Students' Distribution

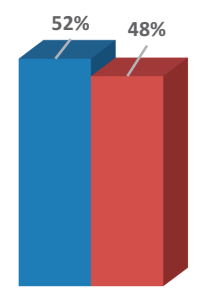

Elementary Stage

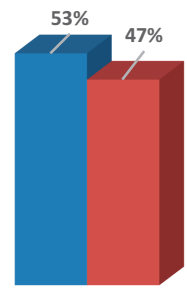

Preparatory Stage

Males Females

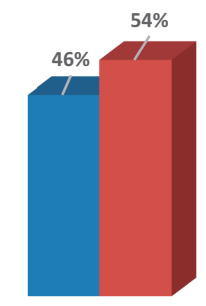

Secondary Stage
Strategy to encounter extremist ideology

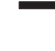


JHASS

3,2

90

(4) North Sinai Governorate is also characterized by an increase in the percentage of students joining technical secondary education (industrial, agricultural and commercial education) compared to general secondary education. This fact may be commensurate with the living conditions of the families residing in North Sinai as shown in the following diagram (Figure 2).

(5) Great attention is paid to social services as well. In the field of health care, for example, a number of major hospitals have been set up by the armed forces in both El-Arish and Sharm El-Sheikh. In the education sector, on the other hand, and at the level of pre-university education, 46 projects have been implemented, including (establishing and raising the efficiency of schools and educational departments in Sinai). Much interest has also been shown in university education, by developing Sinai University in El-Arish and establishing Salman bin Abdul Aziz University.

(6) The degree of accepting extremist thoughts has increased. This can be attributed to the low number of libraries in North Sinai, especially children's libraries in the Sheikh Zuweid area, and hence, there has been primary reliance on local cultures (Ali, 2019). Therefore, there is relative interest in the cultural aspect, although the results of this interest have not yet clearly yielded the required results.

(7) In 2018, there were three cultural palaces, five cultural houses, three theaters and two cinemas in North Sinai. There are 14 public libraries in the governorate (5 in El-Arish, 2 in Sheikh Zuweid and 7 in Bir Al-Abed) and there are 12 children's libraries (4 in El-Arish, 1 in Sheikh Zuweid and 7 in Bir Al-Abed). There are 1,125 mosques and prayer rooms representing $0.8 \%$ of the total number of mosques in Egypt. Some projects have been designed for the cultural sector at a cost of EGP30.9m. Bir Al-Abed Media Complex and other 36 projects related to the Awqaf (endowments) sector have been successfully implemented, at a cost of EGP22,400,000.

(8) Some urban development projects have been initiated in Sinai, with a total worth of about EGP20.8bn, of which EGP16bn is allocated for the construction of about 700 thousand housing units, and EGP2.8bn for the facilities such as drinking water and sanitation services. Taking into account the citizens' social nature, and according to the state's strategy for the development of North Sinai, the state has worked on establishing urban communities that will not sever familial and tribal ties. The state has also taken into consideration the local occupations, especially fishing. The project of establishing Rafah New City, for example, was launched in

Figure 2.

Percentage of distribution of the secondary-level students in North Sinai Governorate (2018/2019)

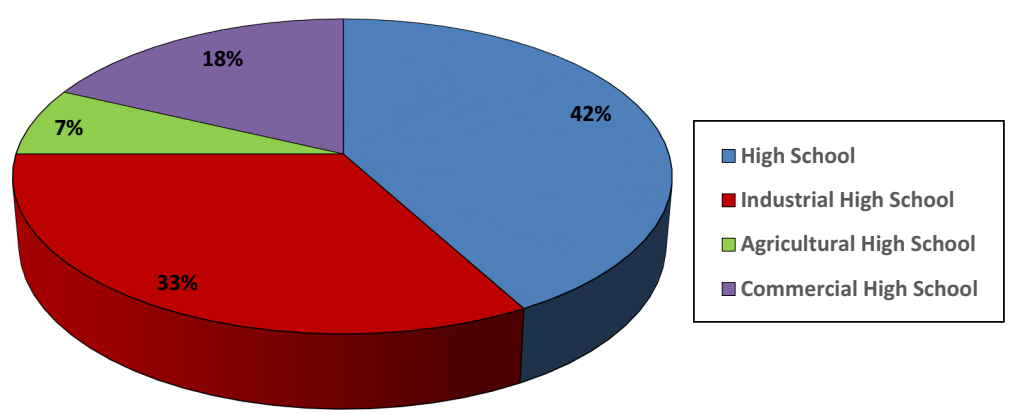


October 2015 and the construction phase ended in April 2018, with a total number of 10,016 housing units.

(9) The population in North Sinai depends mainly on groundwater, and in part on the Nile water and desalinated water. North Sinai currently has three seawater desalination plants in El-Arish, Al-Hasna and Nakhl. Four more desalination plants are being established in Al-Arish, Rafah, Sheikh Zuweid and Bir Al-Abed, and the production capacity of these plants will be about $10,000 \mathrm{~m}^{3}$ per day. There is also a water tank with a capacity of $1,200 \mathrm{~m}^{3}, 7 \mathrm{~km}$ away from the mining area. A water line has been extended for $300 \mathrm{~m}$ from El-Arish.

(10) The state has paid great attention to the development of the transport infrastructure, most importantly the development of airports in the region, such as St. Catherine Airport or Ras Sidr International Airport. The construction works of the Melez-Bardawil Airport began in February 2018.

(11) The number of health units equipped with beds is 13 ; 7 of them are public units built in 2017, and 6 are private units. Despite the decrease in the number of ambulance centers from 83 centers in 2017 to 50 centers in 2018, the capacity of these centers has increased to serve 9 cases instead of 5 cases only.

\section{Political environment}

- There is a relative political stability during the study period. North Sinai Governorate is known for its low rate of political participation, as the percentage of participation in the 2015 parliamentary elections did not exceed $25.3 \%$ (59,351 voted out of a total of 234,635 citizens who have the right to vote).

- The rates of participation in the presidential elections in the 2014 and 2018 rounds were $34.6 \%$ and $30.8 \%$, respectively, and there was a relatively high participation in the vote on the constitutional amendment referendum in April 2019.

- On the level of civil work for civil society organizations (CSOs), North Sinai has been suffering from a clear deficiency in these organizations. North Sinai had only 27 non-governmental organizations (NGOs) in 2016 according to CAPMAS' 2018 Statistical Yearbook, and thus it is classified as the second lowest governorate in Egypt on the number of NGOs, after the South Sinai Governorate, which has only 18 NGOs.

\section{Security environment}

As for the security context, North Sinai has witnessed the most violent and persistent activity of terrorist organizations. A total of $85 \%$ of the total terrorist attacks in Egypt occurred in the governorate during the study period. Therefore, authorities are making great efforts to combat terrorism in the province (Hilal, 2018). These efforts were clearly reflected by the low rate of terrorist activity in the governorate and the decrease in the number of terrorist attacks conducted in Egypt. According to the global index issued in December 2019, the number of terrorist attacks in Egypt decreased during 2019 by $375.5 \%$, and fell from 169 terrorist operations in 2015/2016 to only 45 operations in 2019 , as a result of increased activity to combat terrorist organizations in Sinai. There is 
JHASS

3,2

92

no doubt that this decline in terrorist activity is a result of the pre-emptive strikes launched by the security services on the terrorist cells located there, in addition to what the military operations of the armed forces in combating terrorism witnessed during the study period. The most important pre-emptive strikes launched by the security services are as follows:

Martyr's Right operation (Haq Elshahed). It continued from September 2015 to February 2018 with the aim of eliminating terrorist elements in several regions of North Sinai. Martyr's Right operation focused on encompassing terrorism in Sinai, combing terrorist outposts and destroying terrorists' control on the ground. In four stages, the operation succeeded in exterminating more than (879) terrorists, seizing (741) suspects and terrorists, destroying (135) vehicles, blowing about (38) weapons caches to bits and eradicating more than (139) underground bunkers used by terrorist elements for escaping.

Comprehensive operation to combat terrorism in Sinai 2018. Comprehensive Operation Sinai 2018 aimed at purging the regions in North and Central Sinai of terrorists and groups, pursuing terrorist outposts in the Delta of Egypt and the desert west of the Nile Valley, and preventing them from staying in contact with terrorist elements in North and Central Sinai. In implementation of the instructions of President Abdel Fattah El-Sisi, the operation is going to be continued until the terrorist outposts are eliminated and all strategic directions are secured.

The Comprehensive Operation Sinai 2018 is an unprecedented security achievement; it has succeeded in destroying the infrastructure of terrorist groups and eliminating many terrorist leaders, while successfully securing borders and significantly drying up sources of funding and logistical support. In the context of that success, more than 663 terrorists were obliterated, and about 1,142 individuals from terrorists or pro-terrorism elements were arrested. More than 2,200 explosive devices, more than 1,279 vehicles and 1,261 motorcycles were discovered and destroyed. All these efforts lead to the discovery and destruction of more than 37 tunnels on the border strip in North Sinai, and reducing attempts of infiltration and illegal immigration.

To sum up, the review of the situation in Sinai - in various economic, social, political and psychological aspects - shows that it allowed the creation of an environment conducive to accepting extremist ideology, and provided the opportunity for terrorism to exist in Sinai. The Egyptian state has recognized this fact and has developed a comprehensive strategy for the development of Sinai, through cooperation with its various civil and military institutions to deal with societal problems in Sinai, to prevent intellectual extremism and all forms of extremism.

\section{Second part: a proposed strategy to counter the incubator environment for extremism in Sinai}

President Abdel-Fattah El-Sisi expressed the importance of the current development pursued by the state in Sinai and the future planning for the reconstruction of Sinai. He emphasized that the development of Sinai is a matter of "Egyptian National Security," and development will not be complete if the extremist ideology, which allows the existence of terrorist groups and their hiding among citizens, continues to exist. This correlation between extremism and terrorism forces any serious treatment of extremism to adopt comprehensive development policies (Amin, 2016). This will provide real reform in all of these factors and conditions that allow extremist thoughts to be accepted. 
In this regard, the paper presents a number of practical proposals and implementation mechanisms to deal with the problem of extremist thoughts and the resulting terrorism in Sinai, to achieve the greatest benefit from the development policies pursued by the state in Sinai in general and North Sinai in particular.

Strategy to encounter extremist ideology

\section{Overall strategic aim}

Countering extremist ideology, the main driver of terrorism, requires adopting a comprehensive strategy that is not limited to security confrontation but rather aims at achieving development and stability. The main objective is to change the characteristics of the incubator environment for extremism and terrorism and help create generations that are more aware of and resistant to extremist thoughts.

\section{Foundations of building the strategy}

- Countering terrorism requires addressing six specific aspects: political, security, social, economic, media and religious aspects. Each axis has its own general objectives and mechanisms for countering terrorism and dealing with extremist ideas. Considering these aspects are related, thus they are regrouped and combined into three aspects: political and security; socio-economic; and education and culture.

- Unifying and integrating the efforts to be undertaken and coordinating them. Such efforts should be dealt as a plan with clear objectives, and the procedural mechanisms for implementing them on the ground should be defined as well.

- Security confrontations are necessary at this stage, but more of their successes will be achieved through the support of other economic, educational, cultural and social efforts (Abdel-Rahman, 2001).

- There must be a unified institution to put these aspects into effect and coordinate them to achieve the desired goals. The National Security Council could be the right body to play this role at the level of the entire republic, with sub-committees to follow-up on this role at the governorate level.

\section{First: political and security aspects}

Strategic aim

It is necessary to extend the full sovereignty of the Egyptian state over all regions in the territory of the Egyptian state, the most important of which is the entire territory of the Sinai, taking into account the specificity of some regions, in coordination with the state and under its supervision. 
The proposals, in the field of the political and security axis, seek to achieve a basic goal of maintaining national security to achieve stability and asserting the full sovereignty of the Egyptian state over all regions in its geographical region and the forefront of it, i.e. the entire territory of the Sinai. This is done while accounting for the specifics of some regions (such as frontier governorates: Sinai, Matrouh, New Valley, Red Sea and Aswan), in coordination with state institutions, and under their supervision. It also aims at connecting the people of North Sinai with the homeland and promotes the values of loyalty to new generations of young people. Political proposals are not limited to what is related to politics in the narrow sense, but rather exceeds aspects related to the so-called public policies (such as educational, health and media policies), as well as political formation institutions. These institutions are related mostly to non-political institutions such as the family, school, university, places of worship and the media.

To achieve the strategic aim of the political and security aspects, the suggested policies should work on three aspects: public policies, political upbringing institutions and security policies.

This can be done as follows[1]:

First:public policies

Implementation mechanisms.

- Increasing allocations for education in North Sinai from the budget of the Ministry of Education, to raise the quality of education in North Sinai, as mentioned before.

- Providing special preparation programs for male and female teachers before starting work in North Sinai schools, especially those involved in teaching the Arabic language, religious education, social studies, history and national education. These programs should focus on Sinai's association with the Egyptian state and the sacrifices of the people of Sinai in Egypt's modern history during the 1956 War, Attrition War, October War and Egypt's war on terrorism. (It is preferable to prepare a book on national education with a section about Sinai, to be taught in the governorate's schools.)

- Offering teachers in the governorate's schools more incentives to encourage the distinguished individuals to work in these schools and to select the most outstanding teachers.

- Providing scholarships for outstanding students from these governorates to study in the capital's universities, without abiding by the applicant's residential address rule.

- Paying attention to providing excellent health services to the people of North Sinai, especially in those areas far from the cities, in which health services are scarce (family medicine units, ambulances and frequent medical convoys). $(*)$

- Adopting the idea of providing advanced treatment at the state's expense, for citizens with critical health issues, in the best civil and military hospitals in Cairo. $(*)$

- Making available mobile health units for places in which people cannot reach the governorate's health services. 
- Promoting cultural and youth centers in Sinai (cultural palaces, youth centers and children's libraries) and making good use of the talented individuals in presenting the region's heritage arts (such as musical groups and bands). (*)

- Allocating a percentage of the admissions to the Police Academy and military colleges to the residents of Sinai.

- Complete evacuation of the border area with Gaza, while granting the affected parties wide spaces in areas far from the border, building houses consistent with the Sinaitic houses for them at the state's expense and making them own the pieces of land by virtue of official contracts from the state.

- Ensuring that the media do not use the term "Bedouins of Sinai," which perpetuates racism and discrimination against the people of Sinai $\left(^{*}\right)$, and carefully observing common and respected tribal sensitivities and customs among the people of Sinai, such as veneration of the elder and respect for the accommodations of women and girls (Ali, 2019). (*)

- Issuing directives to offer media space for presenting national models and giving brush-ups on local cultures. People of the frontier governorates can take part in this media space. Moreover, the national Sinai icons can be presented in official and private television (TV) channels, to inform all Egyptians of their heroic acts and sacrifices for the country during the Israeli occupation and after liberation.

- Having many journeys run by the Ministry of Youth for the forerunners and young residents of Sinai to the cities of the Delta and Upper Egypt (Alexandria, Ras AlBar, Hurghada, Luxor, Aswan, Fayoum and Port Said, including forerunners and young people from the rest of the Egyptian governorates). (*)

- Thinking about developing a way to allow a Sinai club to play in the Football League First Division like what happened to one of the Upper Egyptian clubs (to make a deal, for example, with one of the businesspeople to establish a sports club in Sinai, as the case is with El Gouna, Wadi Degla and Pyramids clubs).

- Giving priority in occupying administrative positions in the governorate to competent residents of the governorate, such as heads of directorates of the governorate in the fields of education, health, social solidarity, housing, youth and endowments.

- Allocating part of the government social-protection programs to some of the people of North Sinai, including the unemployed and the poorest members of the North Sinai community (Murad, 2019).

\section{Second: political upbringing \\ Implementation mechanisms.}

(1) Preparing a unified political upbringing program to include the values for the new generations to be brought up on. It is important to ensure that various state institutions as the Ministry of Education, Ministry of Higher Education and Scientific Research, Ministry of Culture, Ministry of Youth and Sports, Ministry of Endowments, Ministry of Social Solidarity, Al-Azhar, the Egyptian Church, the Supreme Council for Media Regulation (SCMR), the National Council for Women, the National Council for Motherhood and Childhood and CSOs, will participate in its preparation and implementation, with the aim of unifying the message for young people in all these institutions. 
JHASS

3,2

96

(2) Organizing courses on civil or civic education for the youngsters and youth of Sinai to breathe the values of citizenship into them $\left(^{*}\right)$. There is a program that was prepared almost 11 years ago in cooperation between the National Council for Youth and United Nations Children's Fund, and two booklets were printed, one for the youngsters and the other for youth, with the aim of offering training in participation, democracy, spreading the values of tolerance, respect for the other and patriotism.

- It is suggested that part of the training should be about Sinai, with more focus on girls (future mothers). These courses are to be held in El-Arish at the Youth City (which has places set up for that), in cooperation between the ministries and relevant entities.

(3) Encouraging political parties to have headquarters in Sinai in an effort to attract the young generation and youth to political participation. (It was noticed that the rates of participation in the last presidential elections decreased compared to the previous elections, and there were high rates of invalid votes as well.)

(4) Taking interest in activating the women's empowerment program in North Sinai, under the supervision of the branches of the "National Council for Women" and the "National Council for Motherhood and Childhood" in North Sinai. This approach is essential for confronting the intellectual extremism with regard to the role played by woman in education and upbringing. Woman should also be given the opportunity to exercise supervision of these efforts (as women in Sinai complain that the "New Arrival Women" are exerting control over these branches at the expense of the women belonging to the tribes of Sinai).

(5) In local or legislative elections, consideration should be given to focusing on the nomination of young people (young men and women) with good reputation and ability to influence others, especially as the constitution has stipulated that $25 \%$ of the seats of local councils, on different levels, be reserved for youth below the age of 25 .

(6) Monitoring and following-up on political performance of local councils to keep an eye on any extremist or biased trends.

Third: security policies

Implementation mechanisms.

- Coordination with the heads of tribes and local leaders with regard to the complete evacuation of the border area with Gaza, covering the area the concerned parties find necessary to be emptied, while providing remunerative compensation in the form of financial sums or pieces of land and houses for those affected by this measure required for tightening up Egyptian national security.

- Enforcing the law on everyone without any exception. This should be done without prejudice to the tribal customs or sensitivities of women and girls (Abdel-Rahman, 2001). Also, it is important to give the influential heads of tribes the opportunity to play a role when implementing the law in some cases, such as allowing the head of tribe to turn any wanted person in to the police without the police's breaking into homes in which women and girls are living to arrest the wanted people. (*) 
- Setting a deadline for the delivery of unlicensed weapons to the heads of tribes, while permitting the licensing of personal weapons in accordance with the law and demonstrating commitment to implement that.

- The President of Egypt using his right to pardon or to reduce the punishment for some cases to which this right can be applied, in consultation with the security authorities and the heads of tribes.

- Holding regular meetings between executives at various levels (political leadership, administrative leadership or ministers) with the heads of tribes of Sinai and representatives of women, youth and civil society in the Sinai, so that their demands can be directly considered.

\section{Second: social and economic aspects Strategic aim}

Transforming the Sinai region into a thriving area of development on the economic and social levels, advancing the Egyptian Sinai citizen according to the various indicators of economic and social development and enhancing the local residents' loyalty and supreme affiliation with the mother country.

To achieve this strategic goal in the social and economic fields, interventions at four levels can be proposed as follows:

Urban reconstruction of the region

These interventions aim to change the pattern of urbanization in the region, by shifting from having small Bedouin communities to having major cities from which Bedouin belonging dissolves and wherein multiple commercial, industrial and agricultural activities are conducted. The aim is to increase and deepen the connection between citizens in North Sinai and these development activities (Amin, 2016). In addition, it is important to increase the state's presence in the governorate, which limits the spread of terrorist organizations there and increases the rejection of extremist thoughts.

Implementation mechanisms.

- Constructing and developing more cities in the governorate will be beneficial to maintaining the process of urban development. A number of new cities have been established in Sinai so far (Rafah New City and New East Port Said), 2,136 housing units have been created in El-Arish alone in an attempt to distribute the relatively high residential densities in this city and 18 villages in the governorate have been built so far during the current study.

- Expanding the patterns of industrial investment within the cities. In every city, a large factory is established (plants for manufacturing fertilizers, petrochemicals, cement, foodstuffs, etc.). The President of the Republic has issued Decision No (70) of 2017 to allocate an area of 78,386.5 acres for the benefit of North Sinai to establish an industrial zone on it. Indeed, a huge number of industrial projects have been 
JHASS

3,2

98

designed within the governorate's development strategy, and they are under implementation.

- Expanding agricultural land reclamation. A total of 400 thousand acres, for example, are reclaimable in Al-Salam Canal plot, and 1.659 million acres in the plain of Wadi El-Arish.

- Investing in education. The idea of establishing universities specialized in important and sophisticated fields that attract students from all over the country, without sticking to the geographical zone system for university admission, can be proposed.

- Building up an intersecting network of roads linking cities with each other, and connecting them with the valley west of the Canal and the South Sinai region. This network has already been implemented and two 40-km long roads have been completed. Some other 1,299 km long roads are being implemented as well. It is important to keep the continuation of implementation at a steady pace, which increases the credibility of the development strategy of North Sinai.

- Establishing an urban development body in North Sinai.

- Activating the role of CSOs, especially those interested in women, as they are responsible for the process of upbringing and inculcating basic ideas and habits in children, to prevent extremism.

- Expanding the role of youth centers to absorb the energies of youth, direct their activities in a positive way and nurture the value of loyalty and work for them.

\section{Tourism development}

Implementation mechanisms.

- Developing natural reserves and tourist centers as a kind of investment in the natural elements in North Sinai. The project of establishing an environmental tourist center on the banks of Al-Bardawil Lake on an area of 1,900 acres, which provides 10,000 job opportunities, may present an example of the tourism potential available in the governorate.

- Large scale establishment of tourist centers, especially medical tourism based on natural herbs and natural remedies. Partnerships with some international tourism companies - in acceptable proportions - in these projects can be allowed to help effectively market such projects and promote tourism in this region.

- Encouraging investors to establish tourist resorts in the region to attract local and international tourists and provide employment opportunities for the local population.

- Working to link tourism activity in South Sinai with tourism activity in North Sinai, especially international conferences and short journeys.

- Organizing tourist groups from North Sinai schools to visit the sights of Cairo, Luxor and Aswan. (*)

Industrial development

Implementation mechanisms.

(1) Converting North Sinai to an industrial zone, by establishing a number of major factories in the new cities, as previously mentioned. 
(2) Establishing a business incubator in the governorate to accommodate the projects. This incubator shall be designated for those wishing to get their own projects off the ground or to implement innovative development ideas under the condition that they neither have the appropriate sites nor the financial capabilities to initiate their projects (Amin, 2016). Hence, this incubator shall be responsible for making the project site available, bearing the expenses of establishment and obtaining licenses and providing financial and administrative support. When the project becomes independent, it leaves the incubator, which opens a new opportunity to embrace another project. $\left(^{*}\right)$

(3) Encouraging youth to be entrepreneurs in small projects through a comprehensive program of training courses (on management and technicalities) with regard to various handicrafts (manufacturing carpets, rugs, textiles, clothes, bags and beadwork) and food products. This will help in making good use of the natural resources of the governorate.

- In-kind support can be provided to participants at the end of the training courses. Small and micro loans can also be offered to start projects while facilitating banking procedures and rendering marketing assistance.

- Contracts can be made with factories and companies to provide the products needed to ensure the sustainability of projects in the governorate. The products can be bought and sold in state-owned outlets. A portion of the aids granted by Egypt's Ministry of Social Solidarity can be allocated to finance small and micro projects.

(4) Publication of the productive families' project, to encourage poor families to generate income from special economic activities in the field of heritage industries known in North Sinai.

Social development

Implementation mechanisms.

- Empowering families in general and women in particular, to increase income independence for many families and reduce their financial needs. According to the results of many studies, the lack of independent income and the fundamental financial needs are both two of the prime drivers of the radicalization of thought, and possibly joining terrorist organizations.

- Planning and implementing training programs for mothers in families, focusing on educational values and the role of mothers in raising young generations. (*)

- Implementing the system of rural women pioneers in the villages of the region and their Bedouin communities. This strategy should be associated with providing a strong training program for women pioneers to convey anti-extremism and antideviation values to families. $(*)$

- Strengthening the national social affiliation, through the educational curriculum, the local and the national media. It is also proposed to hold weekly classes in schools to raise awareness of the participation of the people of Sinai in the national achievements throughout the history of the Egyptian state to instill and consolidate the values of patriotism, loyalty and belonging 
JHASS

3,2

100

- Conducting competitions in the field of sports and in various cultural fields about reading and poetry for citizens of North Sinai, along with providing rewarding incentives for the participants. $\left(^{*}\right)$

- Delivering special care for families affected by the war on terror (families in combat zones and families that have lost some of their members because of the war). This could be achieved through rendering financial assistance, lending psychological and social support and offering special benefits to family members (in the fields of employment and education).

- Organizing medical convoys to help provide health services, and early detection of epidemic and communicable diseases. (The medical sector at Cairo University can take part through the Faculty of Medicine, Faculty of Dentistry, Faculty of Pharmacy and Faculty of Physical Therapy to do this job with its counterparts from other universities.) (*)

- Putting the initiative of President Abdel Fattah El-Sisi, in respect of the detection of hepatitis $\mathrm{C}$ virus and other communicable and epidemic diseases as well as early detection of breast cancer into effect.

- Establishing literacy centers, in coordination with NGOs, preferably near the residences of those who suffer from illiteracy. These centers can be reached without the need for paying any transportation fees. Financial grants can also be disbursed to those who have obtained a literacy certificate to encourage and motivate them.

- Encouraging the establishment of local community development associations in the cities and villages of the region. In addition, assigning civil societies with a central scope of work such as the Egyptian Red Crescent Society will ensure coordination among these societies and will provide the necessary training and encouragement to engage in development programs with economic and social dimensions.

- Encouraging NGOs to engage in the programs for changing rigid values, developing civil trends and embedding citizenship values.

- Holding educational seminars and informative sessions in the cultural palaces and libraries to change trends toward rejecting and renouncing extremism and violence. In addition, libraries can be supplied/provided with specialized books in this regard that can also be distributed free of charge to library goers. $(*)$

- Enhancing the role of social media in strengthening the spirit of cohesion, national belonging and reducing misleading tendencies.

- Establishing a television channel devoted to Sinai, so called "Sinai Channel" that can be broadcasted from El-Arish. (*)

- Establishing a radio station, so called "Sinai." $(*)$

Third: cultural and educational aspects Strategic aim

Attention to the educational and cultural aspects is the cornerstone of all programs to combat extremism and terrorism. Mind development is the basic rule in all 
preventive programs that can be formulated. The basis of terrorism is the extremist ideology that should direct efforts to change it, amend wrong beliefs and eradicate extremist ideas.
Strategy to encounter extremist ideology

To achieve this aim with the educational and cultural dimensions, we suggest moving through three basic channels that represent mainly the cultural and educational axis. Some possible efforts can be made through them, namely, the family, the school and places of worship.

\section{First: the role of the family}

The main objective here is to enable the family to maintain its cohesion, achieve constructive interaction between its members, meet the basic and complementary needs of them and preserve the family existence.

Implementation mechanisms.

(1) Protecting the family from violence and avoiding risks by:

- Adopting mental health and psychological counseling in natural areas of life, such as schools, businesses and health units. This can monitor the tendency toward extremism and violence in the initial stages, so that these people with this tendency can be redirected.

- Establishing units to protect the family from violence and abuse among its members especially women and children. These units should be multidisciplinary and subordinate to the relevant ministries (Ministry of Interior, Ministry of Justice, Ministry of Solidarity and Social Justice, etc.).

- Preparing the necessary professional cadres to work in the family protection units. This can be done through creating multidisciplinary university diplomas in the social, psychological and legal fields related to the multidisciplinary family counseling process.

- Establishing psychological and social counseling units to be affiliated to the juvenile delinquency courts. The objective of this mechanism is to get acquainted with the family conditions of delinquents, try to improve them in a way that helps the family to properly deal with the delinquents, set them on the right track and protect the rest of the family from delinquency.

(2) Helping the family in dealing well with its children:

- Developing parents' skills in dealing with children, and understanding their basic conditions and needs, especially in critical crises (such as going against the law and terrible growth crises in adolescence).

- Developing parental control capabilities in relation to modern technology to which the young generation is attracted (TV, internet, mobile phones, etc.). This can be achieved through organizing special courses to teach parents the principles of control over the youngsters' activities on the internet, mobile phones and TV. $(*)$

- Making good use of the youth centers in the governorate to organize these training courses. 
JHASS

3,2

102

(3) Establishing family counseling offices, whose tasks include:

- Designing and implementing counseling programs for families to help spouses to be aware of the negative parenting methods that promote violence among children. These negative parenting methods could be distinguishing between children, favoring some children over others and treating them cruelly and unkindly. These negative methods can be replaced with positive ones that support the positive self-concept, and contribute to the positive development of children. This could be achieved through parent's understanding, acceptance, tolerance and adopting constructive and fruitful dialogue which will enable everyone to solve the children's problems and surmount the difficulties facing them. $(*)$

- Establishing family counseling offices affiliated to Sharī'ah courts to regulate marriage-related matters, including examining the physical, legal and psychological competence of both parties to the marriage.

- Ensuring that parents deal well with children and care for them after divorce. Family counseling offices should help parents avoid the conflict that results from separation/divorce, as children are considered the main victims of that separation. In addition, Family counseling offices should provide some psychological services to the parties in this conflict.

\section{Second: the role of the school}

The general objective here is to develop the students' way of thinking, not through instructing the students but by allowing them to rely more on research and critical thinking, enhance the values of citizenship and embed positive values. This can be achieved through making good use of the experience of Cairo University in developing the students' research skills and critical thinking.

\section{Implementation mechanisms.}

(1) Changing the teaching and assessment methods in use:

- Working on developing teaching and assessment methods used in schools in a way that achieves the hoped-for development in students' way of thinking.

- Teaching methods should not be based on instruction and memorization but rather on dialogue and discussion.

- Assessment methods should focus on assessing the skills of analysis, inference, understanding and the ability to solve problems.

- Developing the way religious education is taught (Islam and Christianity). Religious education should focus on the daily life practices. It is important to provide a well-established training to religious education teachers, to help them emphasize the concept that religion is a behavior characterized by tolerance and moderation, not inflexibility and harshness.

- Providing a course on "Human Values" to all students without any discrimination based on religion or gender. This will help in minimizing the degree of acceptance of extremism or religious or gender prejudice.

- Providing training on distance learning and introducing e-learning techniques. This requires the creation of an electronic infrastructure that corresponds to the number of students in the governorate. 
- Working on enhancing the image of all types of education without favoring the general education over the technical education. Enhancing the image of some professions is also favored to develop the students' way of thinking by linking education with the real needs of the governorate's labor market.

- It is possible to benefit from Cairo University's experience in teaching critical thinking course. This course should be taught in all the schools of North Sinai without setting an exam in this subject. A very simplified book can be written to include critical thinking skills (a teacher's book and another student's book). Training students in critical thinking will help them to resist rumor and refute the lies and slanders they hear.

(2) Develop students' skills, and help them solve their problems:

- Holding summer classes to reduce the number of dropouts among those who have to work. This will provide them with better opportunities to study their lessons without having to drop out of education.

- Activating the role of school psychologists and social workers, and improving their working conditions. Accordingly, they can perform their roles well in helping students get over various psychological and academic problems, know the students in need of psychiatric care and follow-up on their condition with their families. This should be done in cooperation with the student's families.

- Offering students a number of training courses in schools on issues of problemsolving, decision-making, creative thinking skills and skills to deal with stress $\left.{ }^{*}\right)$. This is to be done at two levels: first: running a program to train some teachers as trainers, such as teachers of philosophy and psychology. Second, these teachers (trainers) shall provide students with trainings in important life skills, social interaction skills, social skills and self-assertion skills.

(3) Develop student activities and urge students to actively participate:

- Opening schools on holidays for students to perform activities of various types and forms. These activities should be organized appropriately under the supervision of the school administration. $\left(^{*}\right)$

- Organizing periodic meetings for students in schools with some of the community's icons and celebrities in various political, cultural and sports fields. These meetings should operate in a way that gives the students the full opportunity to express their opinions and ideas and discuss what these icons and celebrities say. $(*)$

- Supporting classroom and extra-curricular activities (such as simulation models, scientific debates, initiatives and science and technology clubs). The students should be encouraged to submit practical projects that enhance their social and life skills. $(*)$

- Working on increasing the students' participation and their fruitful social interaction through student unions, the class newspaper and the school parliament. $\left(^{*}\right)$

- Holding contests inside schools in relation to various sports, cultural and artistic activities to promote the spirit of cooperation, free competition and team spirit. $(*)$

- Organizing recreational and scientific trips for students to all tourist and scientific attractions, museums and others. $\left(^{*}\right)$ 
JHASS

3,2

\section{4}

- Conducting provincial competitions in all schools (in the three basic educational stages) to discover and support the talents. $\left(^{*}\right)$

- Developing stadiums in schools or identifying stadiums near schools to hold sports competitions in them.

(4) Promoting the role of the teacher who should be considered as role model and an example to follow:

- Putting a structured training program for some teachers (especially teachers of philosophy, psychology, religious education and national education) to work as trainers afterwards. This program should include training in critical and creative thinking skills, developing teaching and assessment methods, improving the skills of effective communication with students and encouraging dialogue and discussion. Some training courses and workshops can be held for this purpose, which would improve the performance of teachers and help them play their role properly. $\left(^{*}\right)$

- Providing financial and moral stimulation for the teachers to make them feel safe and increase their ability to give. This could be done though allocating special allowances for teachers in North Sinai.

- Teachers' active participation in all possible efforts as role models and examples to be followed by the students.

(5) Enhancing cooperation between the family and the school:

- Reducing school dropout rates in cooperation with the family. This should be done through several steps. First, conducting a scientific, psychosocial, social and educational study to identify the reasons behind this phenomenon in the governorate. Second, discussing ways to overcome those reasons, and lastly examining the possibility of bringing dropouts back to schools again.

- Designing and implementing a structured literacy program for parents. These programs should be organized by schools at night in cooperation with adult education. Rewards should be given to those who successfully complete the program. $(*)$

- Providing financial assistance to poor families by exempting their children from all kinds of educational fees. $\left(^{*}\right)$

- Supporting the establishment of parent councils and elected councils in schools in which employees, parents and students participate. The main objective of this mechanism is to reinforce the values of participation, dialogue and democratic education. $(*)$

- Periodic follow-up, by the students' families, to monitor their academic level through a special card. This card is designed to record the scientific level of the students and the progress they make. It shows whether their performance level is improving or falling. This card should include an evaluation of the students' behavior inside the school. (*)

(6) Preserving identity, belonging and strengthening the values of citizenship and democracy:

- Respecting the distinctive culture of Sinai in its various manifestations, while stressing that all the people of the homeland play their role to protect it and make it thrive (Hilal, 2018). The citizens of Sinai have honorable history and have performed great heroic acts in relation to this national duty. 
- Teachers should speak at the beginning of each session, even for a few minutes, about the importance of citizenship, the values of tolerance and acceptance of the other. Some short films to prompt citizens to act this way can be presented. (*)

- Incorporating the values of citizenship, belonging and democratic education into curricula and syllabi in an interesting and effective way.

- Changing some possible negative trends of young people, and amending wrong beliefs about the concept of homeland and citizenship.

Strategy to encounter extremist ideology

- Embedding positive values and supporting moral and educational upbringing through social interaction among students, both inside and outside the classroom.

- Engaging students through practical activities in studying and practicing many positive values, which help to reject violence and extremism, such as the values of tolerance, forgiveness, respect, trust and gratitude. $\left(^{*}\right)$

- Organizing seminars, conferences and workshops to introduce the importance of tolerance, forgiveness and acceptance of others. $(*)$

- Creating electronic applications of video games for children, designed to increase the sense of loyalty and belonging to the country.

\section{Third: religious institutions}

The overall goal is to develop the content of religious discourse, reject religious extremism and improve the personal and professional capabilities of preachers.

Implementation mechanisms.

(1) Mechanisms for developing the content of religious discourse and updating the discourse style:

- Incorporating the values of development into the structure of religious discourse. This religious discourse is directed toward advancing the development process, directing energy into work and achievement, fostering teamwork and values of citizenship and political participation and elaborating personal values that help reinforce all these levels of development.

- Religious sermons should focus on resisting extremist and terrorist ideologies through organized counter-propaganda. These sermons will refute these ideologies, refute their foundations and thwart terrorist propaganda, which tries to brainwash young people and persuade them of destructive terrorist thoughts and spread rumors about the terrorists' ability to do what they do. $\left(^{*}\right)$

- Urging imams (a title of a worship leader of a mosque and Muslim community among Sunni Muslims) to shorten the sermon time in a manner that does not prejudice the intended meanings of the sermon. The sermon's topic should be determined accurately. Imams should prepare it precisely in terms of content, form, presentation and good performance. They should stick to the main point and keep the unity, consistency of the sermon topic to the audience. $\left(^{*}\right)$

- Circulating the good soapbox sermons, regardless of where they have been given or who have preached them. Sermons should deal with important life issues such as the values of tolerance, love, affection, altruism, assistance, forgiveness and remission. Sermons should be kept away from presenting the argumentative issues that cause confusion among the recipients. $\left(^{*}\right)$ 
JHASS

3,2

\section{6}

- Publishing a booklet on the values of citizenship, tolerance and acceptance of the other. These booklets should be distributed in mosques and churches.

- No more publishing of old books of sermons on which some preachers rely on as sources of public speaking. It is important to use books of sermons for trusted scholars.

- Achieving the required balance between the methods of intimidation and invitation in Islam ( $D a$ ' wa: calling others to Islam), and the preponderance of the methods of invitation. Excessive intimidation in trend-changing programs is counter-productive.

(2) Mechanisms for developing the personal and professional capabilities of preachers:

- The preachers should have a more open view on the world and should be more able to see a different role of religion in life, that is, its role in achieving progress and building civilization.

- Proper preparation (education) of individuals before becoming preachers by carrying out an intensive training program. The main objective of this program is to develop their verbal and non-verbal communication skills, persuasion and negotiation skills, etc. This program shall also provide them with some political and economic education and raise their awareness of the challenges facing the state. $\left(^{*}\right)$

- Taking into account personal traits when selecting preachers. This requires broadening the base of selection of preachers so that it can include multiple specializations of those who are qualified to perform this job, and not to be limited to those who are academically qualified.

- Providing a set of psychological, educational and legal tests for preachers prior to their appointment in the mosques. These tests aim at measuring their vision of the world, their various attitudes, their fanatic inclinations and their rigid thinking. These set of tests also show to what extent these preachers are open minded, far-sighted, open to new ideas, flexible, self-disciplined, able to control their emotions, wise and rational. These tests are to be held periodically after appointment. $(*)$

- Holding training courses on a regular basis for preachers during their work to hone their skills in various fields. These training courses are to be provided by specialists in various scientific, psychological, educational, legal and social fields. $(*)$

- Attempting to improve the living conditions of preachers working in North Sinai. This can be done through allocating special allowances for preachers because of the difficulties they face in their work, and working to raise their wages in proportion to the nature of the task entrusted to them.

\section{Conclusion}

After setting out the proposed strategy to counter extremist ideology in North Sinai, a number of observations can be referred to as follows:

- The strategy builds on the existent basic natural and human factors of North Sinai, without any exaggeration or negligence of any of them.

- This strategy is applicable to all frontier governorates, taking into account the relative differences between them. 
- Many of the proposals have already been put into force and adopted by the state. However, they have been mentioned again with implementation mechanisms to emphasis the importance of maintaining and continuing this trend.

- There is a need for conducting many in-depth studies on the various axes of this proposed strategy, and Cairo University can help prepare such studies with the relevant authorities.

- It is recommended to form a committee that oversees the implementation of these proposals. Many representatives of Egyptian ministries should participate in the supervising committee including Ministry of Education, Ministry of Higher Education and Scientific Research, Ministry of Health, Ministry of Finance, Ministry of Endowments, Ministry of Interior, Ministry of Youth and Sports, Ministry of Tourism and Antiquities, Ministry of Social Solidarity, Ministry of Housing and Urban Communities, Al-Azhar, the Egyptian Church, the SCMR and civil society representatives.

- The proposed strategy emphasizes on the philosophy of linking the improvement of living conditions to the elimination of the incubator environment for extremism and terrorism.

\section{Note}

1 Whenever this mark $\left(^{*}\right)$ appears next to any executive mechanism, it means that it can be implemented and launched immediately, and that its implementation does not require any new financial allocations.

\section{References}

Abdel-Rahman, O.A.-H. (2001), "The military geography of the Sinai peninsula and the strategic dimensions of its development”, Unpublished Master Thesis, Faculty of Arts, Cairo University.

Ali, M.S.M. (2019), "Analyzing the dimensions of the terrorist groups' media discourse on social media websites and exploring the elite visions of how to address it: a critical semi logical study", Unpublished PhD Thesis, Faculty of Mass Communication, Cairo University.

Amin, A.A. (2016), "Industrial geography in North Sinai governorate", Unpublished Master Thesis, Faculty of Arts, Cairo University.

Hilal, M.A. (2018), "The phenomenon of international terrorism and its impact on Egyptian national security", Unpublished Master Thesis in Political Science, Faculty of Economics and Political Science, Cairo University.

Murad, H.A.L. (2019), "The media messages sent by the armed religious movements via the internet and their impact on young users", Unpublished $\mathrm{PhD}$ Thesis, Faculty of Mass Communication, Cairo University.

\section{Corresponding author}

Mahmoud Mahmoud can be contacted at: mamahmou@feps.edu.eg

For instructions on how to order reprints of this article, please visit our website:

www.emeraldgrouppublishing.com/licensing/reprints.htm

Or contact us for further details: permissions@emeraldinsight.com 